Clinics in Geriatric Medicine

Falls \& Their Prevention,

Guest editor: Larry Rubenstein, David Ganz

An overview article: Fall Prevention in Australia: policies and activities

\title{
Fall Prevention in Australia: policies and activities
}

Lindy Clemson, Faculty of Health Sciences, The University of Sydney, Cumberland Campus

The University of Sydney, East Street, Lidcombe, New South Wales, Australia 1825.

lindy.clemson@sydney.edu.au

Caroline F Finch, School of Human Movement and Sport Sciences, University of Ballarat

(Mount Helen Campus), University Drive, Mt Helen, Victoria, Australia 3350

c.finch@ballarat.edu.au

Keith D Hill, Musculoskeletal Research Centre and School of Physiotherapy, Faculty of

Health Sciences, La Trobe University and Northern Health, c/o Bundoora Extended

Care Centre, 1231 Plenty Rd, Bundoora, Victoria, Australia 3083; and the National

Ageing Research Institute, 34-54 Poplar Rd, Parkville, Victoria, Australia 3052.

keith.hill@latrobe.edu.au

Gill Lewin, Centre for Research on Ageing, Curtin Health Innovation Research Institute, Curtin University of Technology, 7 Parker Place, Technology Park, Western Australia 6845. G.Lewin@curtin.edu.au 


\section{Synopsis}

Fall prevention recommendations and plans have been prolific in Australia since 1986, however Commonwealth recommendations have rarely been acted upon from a national perspective and the funds for prevention at a national level have been limited. At a state level, while increasing annually, funds for fall prevention have also remained as only a low proportion of total health spending. A number of Australian states have developed their own strategic plans and their activities have developed separately and uniquely, though with reference to national guidelines. We present a perspective of Australian fall prevention policy over time, provide some insights into the current focus and draw on some specific examples of activities from the two most populous Australian states (New South Wales [NSW] and Victoria) and from our largest geographical state spanning Western Australia (WA).

\section{Background}

Australia has a federal system of government which includes the Commonwealth as well as six states and two territories. The states retain considerable constitutional authority and influence in the implementation of health and welfare programs while the Commonwealth government maintains power mainly through its massive tax revenue and funding. ${ }^{1}$ Social and health policy development in Australia centres on negotiations between the increasingly dominant Commonwealth government and the state governments. ${ }^{1}$

Australian health policy has traditionally been about funding and delivery of traditional medical and health care services (hereafter referred to as health services). The Commonwealth has funded states to deliver hospital services and has funded primary care health services with rebate schemes via Medicare Australia. Fall prevention has emerged in 
community and hospital contexts under state health delivered programs, whereas low and high level care (hostel and nursing home) residential facilities have had separate agendas as, in Australia, these services are mainly provided by non-government religious, private or charitable organisations. Current national health reforms could result in a changing landscape for hospital and community with expected shifts in delivery responsibilities between the states and Commonwealth. ${ }^{2}$

\section{Problem recognition and policy development}

Policy is implemented when recommendations are converted into action by government, agendas are defined and there are mechanisms in place to bring policy into action. ${ }^{3}$ Elements of these mechanisms can be legislative, financial or administrative. Fall prevention has gained momentum as an important element of the health policy agenda. The major driver of fall prevention policy has been the recognised financial burden to health care costs associated with fall injuries. ${ }^{4}$ This driver received impetus with a national 2003 report that clearly linked expected cost escalations with population projections for an ageing Australia. ${ }^{5}$ This report indicated that fall-related hospital admissions would double by 2030 and continue to increase unless abated.

Injury prevention and control was first endorsed as a national health priority in 1986 with falls considered as the primary injury problem for older people. ${ }^{6,7}$ National implementation plans for fall prevention emerged in 2001 and again in 2005. These plans were not legislated and their success and implementation has implicitly depended upon cooperation and partnerships between and within government and non-government agencies, professional groups and the community. 
In Australia, public health funding for all types of prevention has been limited to $2.7 \%$ of total recurrent health spending, a small fraction of total health expenditure, ${ }^{8}$ with fall prevention funding an even smaller portion. Since 1998, the Commonwealth has funded a range of projects to guide policy and planning, such as the National Ageing Research Institute (NARI) literature reviews, a national assessment of fall prevention activities in the early 2000’s, and provided several rounds of dedicated one-off grants for innovative approaches, particularly in the community setting. Recent examples include epidemiological modelling to help identify best buys in fall prevention, ${ }^{9,} 10$ identifying the knowledge gaps of exercise professionals in relation to fall prevention, ${ }^{11}$ developing a curriculum to improve this, ${ }^{12}$ and exploring barriers and facilitators of community fall prevention programs. ${ }^{13}$

States have varied with their commitments and some now have dedicated and recurrent funding that provides various forms of leadership, organisation and support, as we discuss later in this article. However, much of the fall prevention activity has been the result of individual health and other services re-framing their agendas and priorities.

\section{Health reform- the current national agenda}

Governments have talked about re-orienting health services by placing the role of preventive health more centrally; however, achieving a systematic balance between prevention and treatment has seen little progress in the past decade in Australia or elsewhere. ${ }^{14}$ A change of government in 2007 saw a commitment to primary health care reform and preventive health reform. So far this has translated into national policy to develop strategies to tackle smoking, obesity and alcohol, all important issues that have a high societal impact. Although ageing is not cited as a national priority for action in these first phases, the Government has stated its support for the 2002 Madrid Plan of Action on Ageing, ${ }^{15}$ with one of its three priority 
directions to advance health and well-being into old age. These include notions of a broad range of health and wellbeing issues. An important shift occurred at a National Summit (2008) where prevention was moved into some prominence with recommendations that called for a shift in focus in ageing from a treatment focussed approach to preventive health care. ${ }^{16}$ Thus these philosophies remain conceptually endorsed but the responsibility for leadership and implementation remains with state and community endeavours.

\section{Policy implementation}

The national guidelines for best practice in fall prevention, released in December 2009, are divided into three practice settings: community care, residential care and hospitals (http://www.health.gov.au/internet/safety/publishing.nsf/content/FallsGuidelines). The guidelines have been developed from expert review, supporting evidence of interventions and, where available, cost effectiveness information. To facilitate uptake they have provided some information on assessment and intervention resources. These guidelines have been widely disseminated and well received by the states with commitments from many of the state government health agencies to actively use them when developing their next strategic plans. Although there is some information on implementation guidelines for hospitals, there is a lack of broader direction for implementation of these guidelines in a sustainable way.

At a Commonwealth level, a National Injury Prevention Working Group has been convened since 2005 with state leaders and Commonwealth policy officers participating to develop and implement priority actions to prevent falls (and other forms of injuries) across the country, whilst recognising jurisdictional boundaries. ${ }^{17}$ Members have a major role in recommending funding investments to senior management, the Director-Generals of Health and Government Ministers. Some of the state-based policy officers, but not all, have some financial delegation 
to allocate funds for the jurisdictions they represent (either national, state or territory) whereas others require more senior executive or Ministerial approval. The group meets regularly to discuss priorities and exchange information.

As residential (nursing home and hostel) care is largely in non-government sectors it has had less integration in fall prevention activities.

\section{Delivering fall prevention: an historical perspective}

Fall prevention activities have traditionally been considered a part of population health and health promotion because of the strong recognition that it is the health sector that bears the costs of fall and fall injuries. In the early 1990s developing prevention activities were largely aimed at key messages and raising awareness amongst the community. However, geriatricians, therapists and nurses who provide health care to older people have long recognised the consequences of frailty and falling and address these issues at the level of the individual older adult. The mid to late 1990s yielded new data on the effectiveness of interventions to prevent falls, further bolstering fall prevention efforts. Over this time, Australian society has experienced large shifts in attitudes to improve understanding that falls can be prevented and that health services need to be actively involved as one of many key stakeholders.

Initially, the consequences of falls (such as fractures or lacerations) were the focus of medical attention and the notion of falls as a preventable entity necessitated a shift in philosophy and service delivery. In the late 1990's, small groups of researchers and clinicians formed interest groups to accelerate the knowledge base in some states. These groups tended to develop in an opportunistic manner with emerging individuals and agencies becoming more involved in fall 
prevention research and practice. Over the past five years, there has been some national coming together of practitioners, researchers and those engaged in policy to debate how to translate fall evidence into practice. ${ }^{17,18}$

The state governments have assumed convening roles to varying degrees of support at service, leadership and organisational levels. On the other hand, health professionals have also played a key role and the national guidelines for fall prevention clearly place doctors, nurses, physiotherapists, occupational therapists and other health professionals at the forefront of intervention delivery. Major points of delivery of fall prevention have been population and patient targeted health promotion messages, the hospital system, acute aged care, community and institutions. Various stakeholders have been engaged, with the type of stakeholder varying widely by state and community context. Stakeholders include aged care workers at local council, home support services, private health care providers, the fitness industry and other exercise professionals, and housing authorities.

The Enhanced Primary Care System (EPC), funded via the Australian Medicare system and extended to allied health in 2004, supports medical practitioner referral to allied health professionals who can offer services for patients with complex and chronic health needs. This system is underutilised and the uptake for fall prevention is unknown, though likely low. The reasons for limited use have been attributed to such factors as organisational barriers, difficulty for medical practitioners in initiating the process ${ }^{19}$ and a lack of understanding of what allied health professionals can offer. ${ }^{20}$ It is potentially an avenue for mobilising the private allied health providers into fall prevention. 
While older people with moderate to high levels of fall risk are often identified through various avenues of the health system, many older people with a history of minor falls or fear of falling just accept this as part of ageing, and may not seek advice from a health professional. ${ }^{21}$ There is a need for tools to identify fall risk early (e.g., Quickscreen; http://www.neura.edu.au/research/facilities/falls-and-balance-research-group/quickscreen) and screening for mild balance dysfunction in order for intervention programs to be undertaken earlier, before secondary deconditioning, balance impairment and loss of confidence magnify the longer term fall risk. ${ }^{22}$

Current efforts to improve the early detection of those at high risk of falls involve developing referral services from Emergency Departments (EDs), which are seen as a point of entry to the health system. However, studies have shown that referral without support for follow up is not effective ${ }^{23}$ and have highlighted the importance of pathways of referral to evidence-based interventions. ${ }^{24}$ In some states, discussions are also emerging with ambulance services.

Australia is a multicultural nation, with the numbers of people from different cultural and linguistically diverse backgrounds projected to increase to over $25 \%$ in the next decade. ${ }^{25}$ There are known issues of unequal access and underutilisation of mainstream services for different cultural groups. ${ }^{26}$ However, there is increasing interest in better understanding the implications of cultural diversity on different health seeking behaviours and how these behaviours should affect the models of delivery for fall prevention. ${ }^{13,27}$

The NSW Stay on Your Feet (SOYF) community multi-strategy program (1992-1996) is an example of a fall prevention program evaluated at a population level. This program demonstrated a reduction in fall-related hospital admissions ${ }^{28}$ and raised community 
awareness of prevention messages. ${ }^{29}$ More recently, a team from the state of Queensland undertook a less resource intensive approach with a SOYF intervention focussing on awareness-raising, physical activity, and working with health professionals. The results were discouraging, with no significant reductions in fall risks or in fall injuries. ${ }^{30}$ However, lessons can be learnt in terms of how to translate evidence into real life contexts and from embedding change within a systems perspective. The evaluators called for a stronger combination of a multi-layered approach to multiple health outcomes (incorporating both a bottom up community development approach together with a top down structural change focus) through embedding fall prevention as core business across both the health system and the community sectors. ${ }^{31}$ This is consistent with other work of Australian researchers recognising that both injury prevention in general, and associated policy setting, requires an ecological approach. ${ }^{32,33}$

At the state level, there is impetus to continue to explore population approaches based on best evidence, with interest in cost effectiveness. There is also recognition of the need to accelerate translation of research into practice and of fall prevention activity across the continuum from rehabilitation to community. For example, two of the 27 inaugural National Health and Medical Research Council (NHMRC) funded Partnership Grants (2009), which aim to enable translation of research into practice and policy, were awarded to fall prevention teams: one in Victoria, a partnership with the Victorian Government Department of Health to better focus state-wide fall prevention activities and test sustainability guidelines and the other in NSW to implement and evaluate new national best practice guidelines.

Knowledge and skills base 
Fall researchers in Australia and New Zealand have had a remarkable international presence enabling local knowledge to be relevant and accessible. The Australian and New Zealand Falls Prevention Society, formalised in 2008 (http://anzfallsprevention.org/index.html), has embraced biennial national fall conferences to bring together stakeholders, health professionals, researchers and policymakers. Some states have had longstanding injury and fall prevention interest groups that have formalised into networks. These networks now have varied levels of state government support, and varied degrees of resources for local symposiums, email exchanges and website information. Also, fall prevention study units have emerged at a post graduate level (e.g. The University of Sydney http://www.usyd.edu.au/courses/?uos=1\&uos_sef_id=OCCP5187_Falls_Prevention_With_Ol der_People_6806; ; and the George Institute for International Health http://www.georgeinstitute.org.au/news-and-events/events/two-day-workshop-injuryprevention-and-falls-prevention) but accessibility could be improved. Education for health professionals at an undergraduate level is improving though not in all sectors. A survey showed that exercise/human movement students’ knowledge of fall risk factors was below the hypothesised benchmark. ${ }^{11}$ While the students reached a reasonable knowledge base in terms of the burden of falls and exercise interventions to prevent falls, their skills in delivering exercise programs was not assessed. Although no similar formal assessment has been conducted in other workforce groups, this example shows that while progress has been made, there is still work to be done to reach a much needed broader workforce with relevant training.

\section{Dimensions of fall prevention}

Physical activity and exercise. As in other countries, physical activity messages have been accepted by older people with walking and gardening the most favoured activities ${ }^{34}$ and 
preferred exercise tending towards light to moderate activities. ${ }^{35}$ While Active Australia campaigns demonstrate some change in activity levels, there are no evident changes in the numbers of older people who are inactive (18\% of 65-75 year olds) or those who are well below the national standards for physical activity (39\%). ${ }^{36}$ The most recent national public health guidelines for physical activity released for older people promote moderate intensity interventions for thirty minutes daily but also now include the notion of strength activities (such as climbing stairs instead of the elevator) and balance activities (such as tandem walking). ${ }^{37}$ This is a huge attitudinal shift in what should constitute sufficient physical activity. Until recently, consideration of the relationship between physical activity promotion strategies and fall risk has largely been ignored by physical activity advocates in this country. ${ }^{38}$ The notion of challenging balance and the uptake of strength activities is slowly being accepted within exercise classes but is yet to be a mainstream philosophy amongst older people. The Otago home-based exercise program ${ }^{39}$ is popular amongst therapists because it is evidence-based and has a manual of instructions. Tai chi is also promoted in some community contexts. There is strong support from the state and national physiotherapy associations, fall researchers and state networks in disseminating information, and more recently, the national fitness association conference featured a series of presentations on fall prevention.

Medication review and management There is a mismatch between the evidence for both reduction of psychotropic medications ${ }^{40}$ and medication reviews by medical practitioners ${ }^{41}$ and of translating such evidence into general medical practice. The latter study ${ }^{41}$ was conducted in Australia and demonstrated that the process requires education by a clinical pharmacist, routinising medicine risk assessments for all older patients into general medical practice followed by medicine reviews of at-risk patients. ${ }^{41}$ There has been an Australian 
Home Medicines Review program since 2001 to fund medical practitioner and pharmacy reviews at the person's own home and to develop a management plan. Uptake has been slow and problems highlighted include difficulties incorporating into regular pharmacy practices and insufficient accredited pharmacists. ${ }^{42}$

Home safety interventions. Sub-acute geriatric wards and rehabilitation hospitals in Australia conduct discharge planning and many people with functional or complex co-morbidities are offered a home visit either pre-discharge or by referral to a community team where home safety, access and independent capacity is assessed, usually by an occupational therapist. Access to such visits varies greatly and is more usual in public hospitals, with older at-risk people the most common recipients. ${ }^{43}$ Referrals in the community are possible to community Aged Care Assessment Teams or private occupational therapists, though referral pathways for the latter are less apparent. Veterans have free access to a pro-active annual occupational therapy home safety assessment and provision of equipment up to \$203 which is consumer price index adjusted (Department of Veterans’ Affairs Home Front Falls and Accidents program). Uptake of this program, which has been running for 13 years and is now offered mostly to World War II veterans, remains low at $10 \%$. Complementary services are offered by Vision Australia, which provides a free service assessing low vision needs for safe mobility and safe negotiation of the environment. Again, access to this service is less known in the general medical provider community.

Bone Health. Australia, although infamous for its sun, still cannot boast a Vitamin D safe population. ${ }^{44}$ Lifestyles for many older people, particularly women, are increasingly associated with indoor activities ${ }^{45}$ and foods are not fortified. Further, our 'Slip slap slop' public health campaign has been very successful in educating people that the sun causes 
cancer. This has led to competing messages between the health benefits of sunlight for bone and muscle health and an over-concern by older people with the potential for developing skin cancer in later life. Negotiations among experts, the Cancer Council, and Osteoporosis Australia have resulted in new guidelines for safe sun exposure. These aim to educate the community that exposing 15\% of the body (arms and legs) is sufficient and that the length of safe time in the sun varies with latitude

(http://www.osteoporosis.org.au/files/internal/howmuchsun.pdf). Unfortunately, as a public health message, these are complex issues that make the core messages less accessible. More recent publications are grappling with how best to present the information to the public. While there remains some debate regarding the merits of widespread vitamin D blood test screening, particularly for frail high falls risk older people, uptake of vitamin D supplementation remains relatively low despite supplements now being more easily available. ${ }^{46}$ While national prevention is currently focussing on the obesity epidemic, for older people, sarcopaenia ${ }^{47}$ and sedentary lifestyles ${ }^{48}$ are also emerging as significant health issues with Osteoporosis Australia leading education for medical practitioners.

\section{A snapshot of fall prevention activities across Australia}

Across Australia, there are diverse approaches to funding and activities across state government and other organisations as well as across the public health, welfare and community sectors. For example, NSW displays a strong government leadership and direction towards services, relationships and processes, Victoria is rich in communitygovernment alliances and WA has adopted a collegial partnership approach to leadership with innovation in utilisation of diverse funding options.

\section{New South Wales}




\section{Historical perspective}

In 2003 the NSW Injury Branch manager successfully lobbied using the cost containment evidence $\mathrm{e}^{5}$ and a 'window of opportunity' argument for investment in fall prevention by the state government. A policy position was defined ${ }^{49}$ and the first state-level dedicated funds provided for fall prevention activities (8.5 million Australian dollars over 4 years, with subsequent recurrent funding). Subsequent work identified a set of population indicators against which the success of this policy could be assessed ${ }^{50}$ (to be discussed in more detail later).

\section{Coordination from a state level}

A more formalized structure was implemented in 2007 with a State Coordinator for fall prevention policy appointed to the Clinical Excellence Commission (CEC), an agency responsible for quality, safety and improvement. The CEC is a board-governed statutory health corporation with the CEO reporting directly to the NSW Minister for Health. In addition fall coordinators were appointed within NSW Health to each of the eight Area Health Services (AHS). Each AHS has formed an AHS Falls Prevention Management Committee, to oversee the implementation of that AHS's Falls Plan. The State Coordinator's role is to provide leadership and direction to these area fall coordinators.

The NSW Falls Prevention Program works within the government health sector raising awareness of fall prevention across the hospital and community continuum. There is also work in forming partnerships with other agencies and in the residential aged care sector which has a community networking and leadership role with a policy direction laid out in a document strategy for 2003-2007. A new NSW state strategic plan is currently being developed based on the 2009 national guidelines and will include an evaluation framework. 
The AHS function differently depending on context and local resources and on the level of integration of existing fall prevention activities that are core business. Rural AHS are at a particular disadvantage due to distance, and limited access to specialist services and staffing.

As an example, the Hunter New England AHS has a population of 840,000, covering 130,000 square kilometers and spanning 25 local government councils. Activities are provided by a range of health staff, and include increasing physical activity options to include strength and balance training and implementing standard screening and assessment tools in community services; phone coaching where older people are identified from the ED who have had a fall and are offered coaching to participate in interventions, with follow-up and information to general practitioners; and dissemination of information through web and newsletters. Current initiatives will extend the phone coaching, target farmers for fall prevention and implement the Stepping $\mathrm{On}^{51}$ group fall prevention program.

The NSW adopted mantra is "falls prevention is everyone’s business"52 with the belief that all health workers and the community need to know. Work with sectors beyond health has been limited but with a desire to increase. The team has worked with the fitness industry (Fitness Australia NSW; http://www.fitness.org.au/) to raise the profile of physical activity for the ageing cohort of baby boomers through developing gyms that are accessible to older people and modules for training, such as the “Older, fitter, better” program. A current statewide project that reflects an evidence-base and a strong interest in increasing both the accessibility and the quality of community exercise options for older people is establishing a web-based fall prevention physical activity directory. Entry to the directory depends on an acceptable degree of balance and strength components, based on evidence -based criteria, and determined by key research experts. Many of the discussions leading to these initiatives 
arose or were developed through a NSW-led Falls Translation Taskgroup that specifically brought researchers, policy makers and practitioners together for the first time in this State. ${ }^{18}$

The NSW Falls Prevention Network (www.neura.edu.au/fallsnetwork), now supported by NSW Health, began in 1993 and its role has expanded to advocacy and influencing policy, sharing resources, disseminating information and providing a network that enables collaborative projects and research. It has $>700$ members and, importantly, aims to remain accessible, low cost and evidence-based. Being situated in a research unit provides an environment supportive of its aims.

The increased profile of fall prevention is reflected by the widespread news media coverage of the state’s April Falls Day activities that span the week beginning April 1. This is an important time to raise community awareness and re-engage health professionals and stakeholders in fall prevention. The light-hearted April fools connotation serves well to impress the positive preventive activities, yet the seriousness of falling is not lost (refer to NSW Falls Prevention Program Newsletter: Falls Link [http://fallsnetwork.neura.edu.au]).

State government funding the broad dissemination of a community program In parallel to the activities of the AHS coordinators and in response to the formal adoption of a prevention and early intervention state policy framework in 2007, followed by a NSW Health strategy for older people launched in 2008, NSW Health has now implemented programs centred around three prevention priorities. These are chronic disease management, coaching services for the management of obesity and the implementation of Stepping On, ${ }^{51}$ an evidence-based multi-faceted fall prevention program. The Stepping On program is being rolled out across NSW in both metropolitan and rural AHS, aiming for a reach of 12-14 
programs of 16-18 participants. The initiative is being supported centrally with a clear direction, a decision making process, resources, recruitment support and networking. This is significant as it is the first time that the government at this level has provided infrastructure support and engaged in the broad dissemination of a fall prevention program.

\section{The Victorian picture}

In the state of Victoria, prevention of falls was first identified as a priority in $1994,{ }^{53}$ and has received dedicated state government funding since 1997. The Department of Human Services Aged Care Branch has led responsibility for planning and policy development for fall prevention among older people and funds most activities at a state level, although other sections of the state service (e.g., acute and sub-acute health) fund fall and mobility clinics and centre- and home-based rehabilitation. As part of its earliest efforts, the Aged Care Branch funded initiatives supporting research and improved fall prevention practice across community, hospital and residential care settings. More recently, this funding has focussed on the community and residential aged care sectors and their interface. A key development since 2000 has been the funding of projects through Primary Care Partnerships (regionally-based health and community services) rather than to a specific health service, aiming to foster interagency collaboration, and streamlining of documentation and service provision. Statebased guidelines for fall prevention in hospitals and residential care facilities, including an overall model of practice, and a range of support materials including on-line staff training programs, have been developed by the Victorian Quality Council (http://www.health.vic.gov.au/qualitycouncil/pub/improve/falls.htm\#vqc).

The Victorian Government fall prevention focus is across the continuum of risk, ranging from health promotion, early risk identification and preventive approaches, through to programs to 
reduce risk in those with high risk of future falls and fractures. The health promotion focus includes linkages with other groups within government including a major physical activity and nutrition program. ${ }^{54}$ Workforce development is recognised as a key element in broadening the reach and translation of research evidence. The Victorian Government has funded a number of multi-strategy initiatives using a train the trainer model of the No Falls Program $^{55}$ and the Otago home-based exercise program, ${ }^{56}$ and a current program developing resources to support wider uptake of evidence-based fall prevention exercise prescription approaches for health professionals. For older people with high fall risk, funded initiatives have included trials of fall prevention assessment and referral for older people presenting to EDs after a fall, as well as working with Ambulance Victoria on initiatives to improve follow-up for older people at home who receive paramedic services, but who are not transported to an ED.

Funding for specialist falls clinics for people with high fall risk began in 1998. Within broad guidelines established by the Government, clinics developed in most regions within the state, although with considerable diversity. ${ }^{57}$ Thirteen Victorian falls clinics participated in a project reporting significant positive outcomes in terms of fall outcomes, and secondary outcomes including balance, mobility and muscle strength outcomes. ${ }^{58}$ Individual falls clinic staff have been supported by a coalition of staff from all falls clinics in the state, which meets twice yearly to discuss recent research, practice issues, and to share resources and innovations (http://www.mednwh.unimelb.edu.au/vic_falls/vic_falls_home.htm).

An essential element to supportive mechanisms across the field of fall prevention has been development of a network of practitioners, policy makers and researchers across the state. This has included regular network meetings, which provide updates on current and recent 
programs and resources to support practice change, and opportunities for exchange of ideas regarding what has worked, and what hasn't worked and why not. A fall prevention resources website has been developed and recently updated, that provides a range of information and resources for older people, and also for health professionals, focussing primarily on the community and residential care settings (http://www.health.vic.gov.au/agedcare/maintaining/falls/). The Victorian Government is also a funding partner in one of the NHMRC Partnership grants, ${ }^{59}$ which aims to improve targeting of evidence-based fall prevention activities, and support improved uptake and translation of this evidence in to relevant agencies, as well as for the broader community.

As part of the ongoing funding for fall prevention, the Victorian Government often incorporates evaluation into project activities, or funds independent evaluations of outcomes. A recent review of sustainable outcomes associated with Victoria government funding highlighted capacity building and increased awareness across the health and broader community as important outcomes, and also options for future directions to build further on current activity (report under review). A fall prevention framework for Victoria for the coming five years, incorporating feedback through this report, other evaluations, and a broad consultation process, is being finalised.

\section{Fall prevention activities in Western Australia}

Fall prevention activities in Western Australia (WA) in the early years were primarily focussed on health promotion activities. The Stay On Your Feet program was first implemented in WA in 1996 following on from the NSW program and in 1998 was adopted by the WA Department of Health Injury Prevention Branch (SOYFWA®). The program 
targeted healthy seniors and focused on fall risk identification and management, operated in partnership with community agencies, and actively involved older people as volunteers.

Prompted by a review of program activities during 1998-2003 and the development in 2004 of the WA Department of Health Falls Policy for Older Western Australians, SOYFWA ${ }^{\circledR}$ was extended to reflect a whole-of-life course approach across hospital, residential aged care, home and community settings. Subsequent (2004-2007) reductions (2.5\%) in the number of people aged 65+ with fall-related presentations to EDs and a 5\% decrease in the number hospital falls were considered indicators of success of the program. ${ }^{60}$

Since 2003, fall prevention activities within the health system have been largely undertaken through collegial partnerships facilitated by the state-based Falls Prevention Health Network. The network is led by a team of expert clinicians supported by a small executive advisory group. Network membership is multi sectoral and multi-disciplinary and includes representation from consumer organisations as well as health professionals, researchers and academics and relevant non-government organisations. ${ }^{61}$ Its major function is to plan and develop evidence-based policy and practice, statewide clinical governance, leadership and engagement, strategic partnerships, and evaluation and monitoring systems.

The most significant piece of work from this network has been the development of a model of care to identify and assist in the coordination of activities. ${ }^{62}$ The aim has been to avoid or delay the first fall, reduce subsequent falls and reduce the risk and severity of injury following a fall. Central to this was the establishment of a Statewide Falls Prevention Education and Training Centre within the Injury Control Centre of WA. In addition to coordinating activities such as fall prevention education and professional development and 
training, the Centre has established a Resources Information Centre which provides a single point of access, including via their website, for information and tools on fall prevention.

A range of activities has been developed to be consistent with the model of care. Four current examples are: 1) The Falls Linkage Independence Program (FLIP, currently being piloted with funding from the Australian Better Health Initiative), which aims to provide a sustainable falls specialist service which integrates with primary care, community care and area health services. 2) The Home Independence Program (HIP) is a multi-component restorative home care service run by an independent aged care provider, which includes fall prevention strategies. ${ }^{63}$ 3) The ED Care Coordination Teams, which provide risk assessment and referral in metropolitan hospitals, as part of the Council of Australian Government's Long Stay Older patients’ Initiative and via the National Action Plan Care Coordinators in rural hospitals. 4) In recognition of the limitation of recommendations and referral only following a fall, Perth Home Care Services (PHCS) in partnership with Sir Charles Gairdner Hospital (SCGH) ED and Falls Clinic developed and trialled a model in which PHCS provides follow up home visits to assist the older person to understand their individual fall risk and implement strategies to reduce it and to act on the recommendations made by the hospital. ${ }^{64}$

Preliminary findings from the evaluation of the FLIP pilot are positive and indicate that individuals are changing their behaviour (e.g. taking more exercise) and increasing in their confidence to perform activities without falling. Results from increasingly rigorous trials of HIP show this program to be effective in increasing functional independence, well being and falls efficacy. ${ }^{65}$ Results from the trial of the PHCS/SCGH collaborative program showed that 
a greater proportion of the group being followed up by PHCS did go on to implement recommendations made by the hospital than did those in the hospital-only group. ${ }^{64}$

\section{Fall and fall injury data: determining population impact}

The development of policy initiatives, including the setting of funding priorities and directions, as well as assessing the impact of any implemented programs requires accurate information at a population level. There is no overarching national mandate covering the systematic collection of fall and fall injury data nationally. The only routinely collected sources of data relate to the national mortality data collections, the National Coronial Information System (NCIS) and hospital admissions, where fall cases are identified by specific International Classification of Disease (ICD) external cause codes. Unfortunately, the national mortality data collections are known to under-report fall-related deaths because they rely on certifications of falls as the underlying cause of death, an item that is not always recorded in the death certification process. ${ }^{66}$ The NCIS is also somewhat limited as a source of severe fall injury data because, overall, fall-related deaths have a relatively low level of coroner-certification. ${ }^{67}$

The best source of Australian fall injury data comes from routinely collected hospital admissions data, with the most recent figures relating to the 2005-06 financial year. ${ }^{68}$ This $^{2}$ latest national report shows that the rate of fall related hospitalisations in Australians aged 65+ years has increased between 1999-2000 and 2005-06, though there was also a suggestion of a decrease in the rate of femur factures as a specific diagnosis over this same period. Most jurisdictions have not published specific fall data, but some recent trend analyses of hospitalisations in NSW have suggested a stabilisation of rates of hip fracture (but not 
numbers of cases) ${ }^{69}$; a decrease in wrist fractures in older people ${ }^{70}$ and an increase in fallrelated pelvic fractures. ${ }^{71}$

There has been considerable interest in the development of local indicators against which to measure success of both agency and government fall prevention initiatives. In NSW, one specific mortality metric (fall-related deaths) and four hospital separations-based metrics (fall-related hospitalisations/hospitalisations resulting in death; hospitalised hip

fractures/pelvic fractures) have been recommended as indicators for that state. ${ }^{50}$ In recognition of the importance to prevention efforts of the settings in which the fall injuries occur, the NSW work also recommended a data quality metric describing the completeness of ICD-coded data with regards to place of injury. ${ }^{50}$

Ongoing monitoring of falls and fall injury will be required to fully support the ongoing implementation, sustainability and evaluation of fall prevention programs across Australia. At this stage, routinely collected deaths and hospital separations data are likely to be the best ongoing sources for this. Two states (Victoria and Queensland) also have very good collections of ED presentations data that could also provide valuable insights into the incidence and patterns of non-severe fall injury. ${ }^{72}$ Data linkage efforts in several states have also been found to provide more accurate estimates of fall incidence and fall-related mortality, after adjusting for multiple admissions for the same initial fall. ${ }^{73,66}$

\section{Challenges and future directions}

A number of major challenges persist. Implementation of prevention across the health sector has not been equitable and fiscal constraints have been felt at the local level with staff shortages. Indeed, increasing activity and expertise in one area often means a reduction of 
services in another. In some states more so than others, there has been a retreat by health services in engaging with the community in preventive health initiatives, for example, with community teams having a focus restricted to assessment and acute care. A shift in government policy to prevention is welcome. ${ }^{2}$ There are further challenges ahead with the national health reform agenda, which is envisaged to be a re-organisation at the level of health services. As Wise and Nutbeam ${ }^{14}$ note, increasing activities beyond the health sector are needed to achieve wider population outcomes but activities need clear leadership from and partnership with the health sector. Determining the best value for the limited dedicated funding available remains the key challenge, as well as being able to mount a sound business case for increased resources to be allocated to fall prevention.

At a practice level, the major challenges relate to building sustainability into many fall prevention initiatives that are provided with time-limited funding. Achieving improved outcomes relates both to improved detection of early fall risk and working with older people to maximise sustained participation in evidence-based fall prevention initiatives. There are also clearly issues around awareness and access to services when needed and strengthening of pathways between referral and service providers.

\section{Conclusion}

The committed grounds-up fall prevention activities have provided a strong and collegial environment for robust fall prevention activities in Australia. There are active fall prevention networks, increasing commitment at state and local levels, champions emerging, and activities crossing sectoral boundaries. Education, workforce training, and population reach are key issues. Further, there is a commitment to continue to improve data systems and monitoring, with a strong view to evaluating policy outcomes. 
Despite strong growth in the available research evidence of what works in fall prevention in community and hospital and residential care settings, fall related hospitalisation rates in Australia have not declined in the past 10 years. ${ }^{68}$ There is a need for a strong focus on translational and sustainable fall prevention across all settings in coming years in an attempt to reduce these unacceptably high rates. There is also a need for a coordinated approach with substantial increase in preventive and rehabilitative funding available for the area of fall prevention on a national and a state basis. Despite there being two and a half times as many falls as motor vehicle accidents causing hospitalisation annually in Australia ${ }^{8}$ and the length of stay for the average fall related hospitalisation being $50 \%$ longer than the average motor vehicle related hospitalisation, the resources allocated to fall prevention remain small in comparison to the highly effective long term motor vehicle accident prevention policies and programs and related rehabilitation. There is a need for a similar strong, long term, and well resourced commitment to fall prevention at a national and state level. 


\section{Acknowledgements}

Caroline Finch was supported by an NHMRC Principal Research Fellowship. 


\section{References}

1. Kendig, H, Phillips, R. Health, economic and policy implications of an ageing Australia. In: Phillips R, editor. Generational Change and new policy challenges Australia and South Korea. Sydney: Sydney University Press, 2007.

2. National Health and Hospitals Reform Commission. A healthier future for all Australians: Final Report 2009. Canberra: The Australian Government, 2009.

3. Palmer, GR, Short, SD. Health care \& public policy. An Australian analysis. 3rd ed. South Yarra: Macmillan, 2000.

4. Moller, J. Changing resource demands related to fall injury in an ageing population. Sydney: NSW Health Injury Policy Unit \& Injury Risk Management Research Centre, The University of New South Wales, 2000.

5. Moller, J. Projected costs of fall related injury to older persons due to demographic change in Australia. Canberra: Commonwealth Department of Health \& Ageing., 2003.

6. Commonwealth Department of Health and Family Services and Australian Institute of Health and Welfare. National Health Priority Areas Report: Injury Prevention and Control 1997. Canberra: Department of Health and Family Services and Australian Institute of Health and Welfare, 1998.

7. Commonwealth Department of Human Services and Health. Better health outcomes for Australians. National goals, targets and strategies for better health outcomes into the next century. In: Prior M, editor. Canberra: Australian Government Publishing Service, 1994.

8. Australian Institute of Health \& Welfare. National public health expenditure report 2005-6. Canberra: AlHW, 2008.

9. Day, L, Finch, C, Harrison, J, Horeau, E, Segal, L, Ullah, S. 2010 (in press), Modelling the population level impact of a proven falls intervention for community dwelling older people: Tai-Chi. Injury Prevention, Vol. pp.

10. Day, L, Hoareau, E, Fnch, C, Harrison, J, Segal, L, Bolton, T, Bradley, C, Boufous, S, Ullah, S, the National Injury Prevention Working Group. Modelling the impact, costs and benefits of falls prevention measures to support policy-makers and program planners. Melbourne, Australia: Monash University Accident Research Centre, 2008.

11. Sturnieks, D, Finch, C, Close, J, Tiedemann, A, Lord, S, Pascoe, D. 2010, Exercise for falls prevention in older people: assessing the knowledge of exercise science students. Journal of Science and Medicine in Sport, Vol. 13, pp. 59-64.

12. Finch, C, Lord, S, Close, J, Pascoe, D, Sturnieks, D, Tiedemann, A, Twomey, D. Development of a workforce education program for exercise practitioners in falls prevention and exercise prescription for older people.: Prepared for the Australian Government Department of Health and Ageing. , 2008.

13. Clemson, L, Mathews, $M$, Dean, C, Lovarini, M, Alam, $M$. Translating research into practice: Sustainability of a community-based falls prevention program in minority communities. Lidcombe: University of Sydney. Funded by Department of Health \& Ageing Falls and Injury Prevention Community Grants Program 2007, 2008.

14. Wise, M, Nutbeam, M. 2007, Enabling health systems transformation: what progress has been made in re-orienting health services? Promotion \& Education, Vol. 2, pp. 23-27.

15. United Nations. Report of the Second World Assembly on Ageing, Madrid, 8-12 April 2002 (United Nations publication, Sales No. E.02.IV.4), chap. I, resolution 1, annex II, 2002.

16. Kendig, H. Communique on the 2020 Summit: Ageing well Sydney: Ageing, Work and Health Research Unit, University of Sydney, 28 April 2008.

17. Finch, C, Day, L, Donaldson, A, Segal, L, Harrison, J. 2009, Determining policy-relevant formats for the presentation of falls research evidence. Health Policy, Vol. 93, pp. 207-213. 
18. Poulos, RG, Zwi, AB, Lord, SR. 2007, Towards enhancing national capacity for evidence informed policy and practice in falls management: A role for a "Translation Task Group"? Australia and New Zealand Health Policy, Vol. 4 pp. 1-7.

19. Preen, D, Bailey, B, Wright, A. 2006, Willingness of general practitioners to participate in enhanced primary care discharge care planning. Medical Journal of Australia, Vol. 184, pp. 90-1.

20. Wilson, S, Marks, R, Donohoe, S, Chapman, M, Zwar, N. 2004, General practitioner multidisciplinary skills for enhanced primary care. Aust. Family Physician. 2004;33:479-80. Australian Family Physician, Vol. 33, pp. 479-80.

21. Mackintosh, S, Hill, K, Dodd, K, Goldie, P, Culham, E. 2005, Falls and injury prevention should be part of every stroke rehabilitation plan. Clinical Rehabilitation, Vol. 19, pp. 441-51.

22. Hill, K. 2009 Invited commentary: Don't lose sight of the importance of the individual in falls prevention interventions BMC Geriatrics, Vol. 9, pp. 13.

23. Russell, M, Hill, K, Blackberry, I, Dharmage, S, Giummarra, M, Schwartz, J, Dorevitch, M, Ibrahim, J, Dalton, A, Day, I. In press, A randomized controlled trial of a multifactorial falls prevention intervention program for older fallers presenting to an ED. Journal of the American Geriatrics Society, Vol. pp.

24. Clemson, L. 2010, Prevention of falls in the community: is successful in trial settings, but translation into practice remains a challenge. British Medical Journal, Vol. 340 pp. 10421043.

25. Bradley, C, Harrison, JE. Fall-related hospitalisations among older people: Sociocultural and regional aspects. Injury Research and Statistics Series, Number 33. Canberra: Australian Institute of Health and Welfare, 2007:1-47.

26. Cardona, B, Chalmers, S, Neilson, B. Diverse strategies for diverse carers: the cultural context of family carers in NSW. Sydney: Research report for the NSW Department of Ageing, Disability and Home Care, 2006.

27. Yang, XJ, Haralambous, JA, Hill, K. 2008, Older Chinese Australians' understanding of falls and falls prevention: exploring their needs for information. Australian Journal of Primary Health, Vol. 14, pp. 36-42.

28. Kempton, A, van Beurden, E, Sladden, T, Garner, E, Beard, J. 2000, Older people can stay on their feet: Final results of a community-based falls prevention programme. Health Promotion International, Vol. 15, pp. 27-33.

29. Barnett, LM, van Beurden, E, Eakin, EG, Beard, j, Dietrich, U, Newman, B. 2004, Program sustainability of a community-based intervention to prevent falls among older Australians Health Promotion International, Vol. 19, pp. 281-288.

30. Hughes, W. Preventing Falls in Older Adults Project: Stay Active, Stay Independent, Stay On Your Feet: Research report: Monash University Accident Research Centre, 2007.

31. McClure, R, Hughes, K, Ren, C, McKenzie, K, Dietrich, U, Vardon, P, Davis, E, Newman, B. 2010, The population approach to falls injury prevention in older people: findings of a two community trial. . BMC Public Health Vol. 10:79 doi:10.1186/1471-2458-10-79, pp.

32. Bowen, S, Ziwi, A. 2005, Pathways to "evidence-informed" policy and practice: A framework for action. PLoS Medicine, Vol. 2, pp. 600-605.

33. Hanson, D, Hanson, J, Vardon, P, McFarlane, K, Lloyd, J, Müller, R, Durrheim, D. 2005, The injury iceberg: An ecological approach to planning sustainable community safety interventions. . Health Promotion Journal of Australia, Vol. 16, pp. 5-10.

34. National Ageing Research Institute. Participation in physical activity amongst older people. Melbourne: NARI, 2003.

35. Bauman, A, Bellew, B., Booth, M., Hahn, A., Stoker, L., Thomas, L. 1996, NSW Health Promotion Survey 1994. Vol. pp.

36. Armstrong, T, Bauman, A, Davies, J. Physical activity patterns of Australian Adults Canberra: Australian Institute of Health and Welfare, 2000. 
37. Sims, J, Hill, K, Hunt, S, Haralambous, B. 2009, Physical activity recommendations for older Australians. Australasian Journal on Ageing, Vol. 28, pp. 139-143.

38. Sherrington, C, Lord, SR, Finch, CF. 2004, Physical activity interventions to prevent falls among older people: update of the evidence. Journal of Science \& Medicine in Sport., Vol. 7, pp. 4351.

39. Campbell, AJ, Robertson, MC, Gardner, MM, Norton, RN, Tilyard, MW, Buchner, DM. 1997, Randomised controlled trial of a general practice programme of home based exercise to prevent falls in elderly women. British Medical Journal, Vol. 315, pp. 1065-69.

40. Campbell, AJ, Robertson, MC, Gardner, MM, Norton, R, Buchner, DM. 1999, Psychotropic medication withdrawal and a home-based exercise program to prevent falls: A randomized, controlled trial. Journal of the American Geriatrics Society, Vol. 47, pp. 850-853.

41. Pit, SW, Byles, JE, Henry, DA, Holt, L, Hansen, V, Bowman, DA. 2007, A Quality Use of Medicines program for general practitioners and older people: a cluster randomised controlled trial. Medical Journal of Australia, Vol. 187 pp. 23-30.

42. Kralik, D, Visentin, K, March, G, Anderson, B, Gilbert, A, Boyce, M. 2008, Medication management for community -dwelling older people with dementia and chronic illness. Australian Journal of Primary Health, Vol. 14, pp. 25-35.

43. Lannin, N, Clemson, L, Mcluskey, A. 2010, A survey of the current pre-discharge home visiting practices of occupational therapists in New South Wales, Australia Submitted for publication, Vol. pp.

44. Diamond, TH, Eisman, JA, Mason, RS, Nowson, CA, Pasco, JA, Sambrook, PN, Wark, J. 2005, Vitamin D and adult bone health in Australia and New Zealand: a position statement. Medical Journal of Australia, Vol. 182, pp. 281-285.

45. AlHW: Bennett, SA, Magnus, P, Gibson, D. Obesity trends in older Australians. Bulletin no. 12 Canberra: Australian Institute of Health \& Welfare, 2004.

46. Reginster, J. 2005, The high prevalence of inadequate serum vitamin D levels and implications for bone health. Curr Med Res Opin, Vol. 21, pp. 579-86.

47. Fiatarone Singh, MA, Singh, NA, Hansen, RD, Finnegan, TP, Allen, BJ, Diamond, $T H$, Diwan, $A D$, Lloyd, BD, Williamson, DA, Smith, EUR, Grady, JN, Stavrinos, TM, Thompson, MW. 2009, Methodology and baseline characteristics for the Sarcopenia and Hip Fracture study: a 5year prospective study. J Gerontol A Biol Sci Med Sci, Vol. 64, pp. 568-74.

48. Bauman, A, Owen, N. 1999, Physical activity of older Australians: epidemiological evidence and potential strategies for health gain. Journal of Science, Medicine and Sport, Vol. 2, pp. 30-41.

49. New South Wales Department of Health. Management Policy to Reduce Fall Injury among Older People: Detailed Strategies and Performance Requirements 2003-2007. Sydney: New South Wales Department of Health, 2003.

50. Dowling, A, Finch, C. 2009, Baseline metrics for measuring progress in preventing falls injury in older people. . Australian and New Zealand Journal of Public Health, Vol. 33, pp. 413-417.

51. Clemson, L, Cumming, RG, Kendig, H, Swann, M, Heard, R, Taylor, K. 2004, The effectiveness of a community-based program for reducing the incidence of falls among the elderly: A randomized trial. Journal of American Geriatrics Society, Vol. 52, pp. 1487-1494.

52. NSW Government. Towards 2010: planning for our changing population. 1st year progress report. Sydney: DADHC, 2009.

53. Victorian Department of Health. Taking Injury Prevention Forward-Strategic Directions for Victoria Melbourne, 1994.

54. de Silva-Sanigorski, AM, Bolton, K, Haby, M, Kremer, P, Gibbs, L, Waters, E, Swinburn, B. 2010, Scaling up community-based obesity prevention in Australia: background and evaluation design of the Health Promoting Communities: Being Active Eating Well initiative. BMC Public Health., Vol. Feb 12, pp. 65. 
55. Day, L, Fildes, B, Gordon, I, Fitzharris, M, Flamer, H, Lord, S. 2002, Randomised factorial trial of falls prevention among older people living in their own homes. British Medical Journal., Vol. 325, pp. 128.

56. Robertson, MC, Campbell, AJ, Gardner, MM, Devlin, N. 2002, Preventing injuries in older people by preventing falls: a meta-analysis of individual-level data. Journal of the American Geriatrics Society, Vol. 50, pp. 905-11.

57. Hill, K, Smith, R, Schwarz, J. 2001, Falls Clinics in Australia: A survey of current practice and recommendations for future development. Australian Health Review, Vol. 24, pp. 163-74.

58. Hill, K, Moore, K, Dorevitch, M, Day, L. 2008, Effectiveness of falls clinics: an evaluation of outcomes and client adherence to recommended interventions. Journal of the American Geriatrics Society, Vol. 56, pp. 600-608.

59. Day, L, Finch, C, Hill, K, Haines, T, Clemson, L. Evidence based targeting of statewide strategies for preventing falls among community dwelling older people in Victoria: NHMRC Partnership grant ID 546282, 2010.

60. Lomman, A, WA Department of Health. Working towards integrated falls prevention and management - A Western Australian perspective Active Ageing SA, Falls Seminar - 21st February 2007. Perth, 2007.

61. Government of Western Australia. Health Networks - Collaborative health care planning for the whole community Perth: Department of Health, 2010.

62. Department of Health, WA. Falls Prevention Model of Care for the Older Person in Western Australia. Perth: Health Networks Branch, Department of Health, 2008.

63. Lewin, G, Calver, J, McCormack, B, Coster, C, O'Connell, H, Wheeler, B, Smith, J, vanderMeulen, S. 2008, The Home Independence project [online]. Geriaction, Vol. 26, pp. 13-20.

64. De San Miguel, K, Smith, J. Community Care and Hospital Based Collaborative Falls Prevention Project - Final Report. In: Chain S, editor. Perth: Western Australia: Silver Chain, 2009.

65. Lewin, G, Vandermeulen, S. 2010, A non-randomised controlled trial of the Home Independence Program (HIP): An Australian restorative programme for older home-care clients. Health and Social Care in the Community, Vol. 18, pp. 91-99.

66. Hindmarsh, D, Hayen, A, Finch, C, Close, J. 2009, Relative survival after hospitalisation for hip fracture in older people in New South Wales, Australia. Osteoporosis International, Vol. 20, pp. 221-229.

67. Irwin, M, Hayen, A, Finch, C. Methodological issues in using routinely collected electronic population mortality data: guidelines for using the national coroners information system for fatal injury surveillance in NSW, 2008:Available from http://www.irmrc.unsw.edu.au/documents/NCISreport08.pdf.

68. Bradley, C, Pointer, S. Hospitalisations due to falls by older people, Australia 2005-06. Injury research and statistics series. Adelaide: AlHW, 2008.

69. Boufous, S, Finch, C, Lord, S. 2004, Incidence of hip fractures in NSW: are our efforts having an effect?. Medical Journal of Australia, Vol. 180, pp. 623-626.

70. Boufous, S, Finch, C, Lord, S, Close, J, Gothelf, T, Walsh, W. 2006, The epidemiology of hospitalised wrist fractures in older people, New South Wales, Australia. Bone, Vol. pp. 1144-1148.

71. Boufous, S, Finch, C, Lord, S, Close, J. 2005, The increasing burden of pelvic fractures in older people, New South Wales, Australia. Injury, Vol. 36, pp. 1323-1329.

72. Boufous, S, Finch, C, Close, J, Day, L, Lord, S. 2007, Hospital admissions following presentations to emergency departments for a fracture in older people. Injury Prevention, Vol. 13, pp. 211214.

73. Boufous, S, Finch, C. 2005, Estimating the incidence of hospitalized injurious falls: impact of varying case definitions.[erratum appears in Inj Prev. 2006 Apr;12(2):135]. Injury Prevention, Vol. 11, pp. 334-6. 